\title{
Incorporating Geogebra into Teaching Circle Properties at High School Level and it's Comparison with the Classical Method of Teaching
}

\author{
Vesa Mollakuqe ${ }^{1}$, Shpetim Rexhepi ${ }^{1 \star}$, Egzona Iseni ${ }^{1}$
}

${ }^{1}$ Mother Teresa University, Skopje, NORTH MACEDONIA
${ }^{\star}$ Corresponding Author: shpetim.rexhepi@unt.edu.mk

Citation: Mollakuqe, V., Rexhepi, S., \& Iseni, E. (2021). Incorporating Geogebra into Teaching Circle Properties at High School Level and it's Comparison with the Classical Method of Teaching. International Electronic Journal of Mathematics Education, $16(1)$, em0616. https://doi.org/10.29333/iejme/9283

\section{ARTICLE INFO}

Received: 1 Jul. 2020

Accepted: 7 Sep. 2020

\begin{abstract}
The most influential books on geometry are those of Euclid called "Elements". In our century, in addition to classical learning, various interactive software are used in teaching geometry. Among them, we can mention Geogebra.

GeoGebra is an interactive math measurement program that consists of teaching and learning from elementary to university level. This software is offered as a pedagogical and mathematical aid tool. GeoGebra helps in teaching math because using this software, students see different mathematical formulas, algebraic and geometric presentations.

In this paper, using GeoGebra software, the pedagogical, methodological, and statistical data into teaching circle properties are presented. The study involved 112 students. Of these $40 \%$ excellent, 35\% average, 25\% below average. The research aims to prepare high school students aged 15-18, from grades 1, 2, 3, and 4 in teaching, working, and explaining geometry through Geogebra software. Special emphasis is placed on the circle properties and their presentations.

This content includes the district tangent, the potency, the application of the circle in regular polygons with special emphasis on the inscribed, circumscribed circle in the equilateral triangle, and other important properties.
\end{abstract}

Keywords: software, geometry, circle, pedagogical aspect

\section{INTRODUCTION}

The circle is a flat figure of special importance. The elements of the circle, the regular polygon inscribed in circle and the circle circumscribed about the regular polygon, represent a very important part in explaining it. As a result, we are always looking for a facilitation and tangible examples in teaching and learning.

Nowadays, software is presented to us as the most applicable to students, seeing that more and more students are connected to technology.

GeoGebra is a highly used and attractive software tool for students. Using it, students can construct figures and gain a higher understanding while doing it.

The classic method is outdated and for the younger generations it is as vague as it is unattractive. In the classical method, students construct and practice accuracy on their own, but it is difficult to comprehend the figures. As a result, the chances of giving up are high. 


\section{SOME PROPERTIES OF THE CIRCULAR LINE}

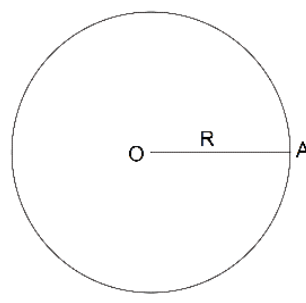

$O$, center
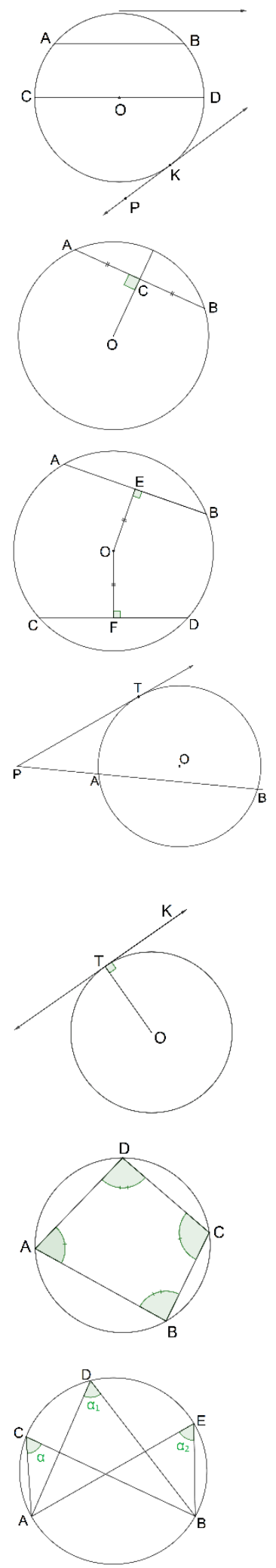

$|O A|=R$, radius



$|A C| \cdot|B D|=a c+b d$

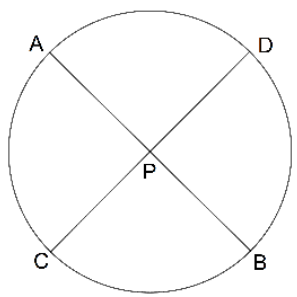

$O C \perp A B \Leftrightarrow|A C|=|C B|$



$O E \perp A B, O F \perp C D$

$|O E|=|O F| \Leftrightarrow|A B|=|C D|$


$\left|P P_{1}\right|=2 \sqrt{P P_{1}}$

$|P B|=\left|B P_{1}\right|=|A B|=\sqrt{R}$



$m\left(P \hat{A} P_{1}\right)=90^{\circ}$

$|T P|=\left|T P_{1}\right| \Rightarrow m\left(O \widehat{T} O_{1}\right)=$
Inscribed angle

$$
\begin{aligned}
& m(B \hat{A} C)=\frac{m(B \hat{O} C)}{2} \\
& =\frac{m \widehat{B C}}{2}
\end{aligned}
$$

$$
m(A \widehat{T} K)=\frac{m(\widehat{A L T})}{2}
$$

$$
|A B|=2 R \Rightarrow m(A \hat{C} B)
$$

$$
m(A \hat{O} B)=m(\widehat{A K B})
$$

$$
\begin{array}{r}
|A B|=2 R \Rightarrow m(A C B) \\
=90^{\circ}
\end{array}
$$

measurement of inscribed
angles facing the same intercepted arc is equal

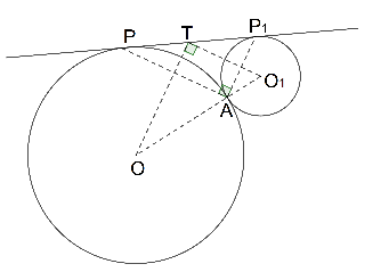



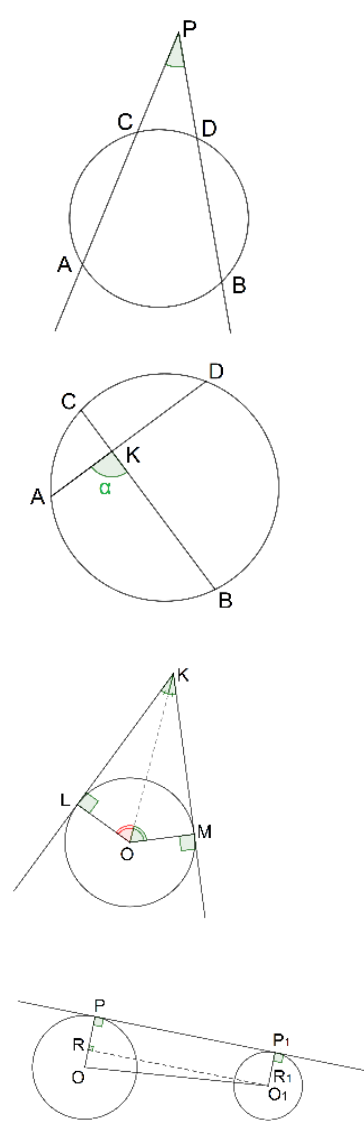

$\left|P P_{1}\right|=\sqrt{\left|O O_{1}\right|-\left(R-R_{1}\right)^{2}}$

$|K L|=|K M|$

$m(L \widehat{K} O)=m(M \widehat{K} O)$

$m(K \hat{O} L)=m(K \hat{O} M)$
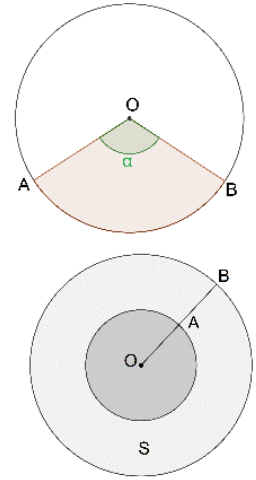

$|O B|=R$

$|O A|=r$

$S=\left(R^{2}-r^{2}\right) \pi$

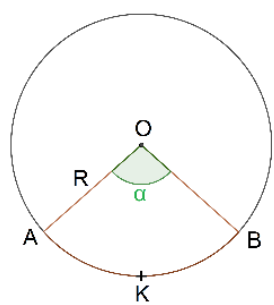

Circumference $=2 \pi R$ Arc length

$|\widehat{A K B}|=\frac{2 \cdot \pi \cdot R}{360} \cdot \alpha$

Area $=\pi R^{2}$

$A(A O B)=\frac{\pi R^{2}}{360} \cdot \alpha$

$\left|A O_{1}\right|=\left|P P_{1}\right|$

$=\sqrt{\left|O O_{1}\right|^{2}-\left(R+R_{1}\right)^{2}}$

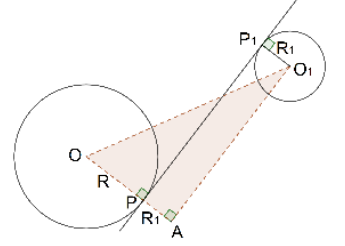

\section{The tangent line}

The line that has only one point in common with the circle is called the tangent of the circle. The tangent of the circle and the radius passing through the meeting point are normal to each other.

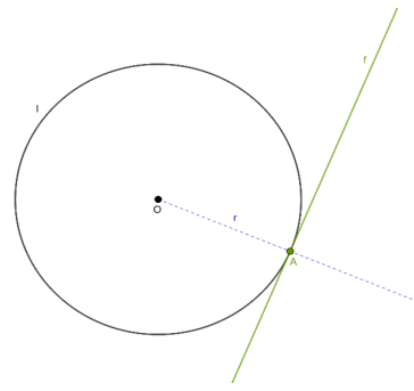

Figure 1. Tangent line to a circle

Example 1. Let $l(O, r)$ be a circle and a line. Construct the tangents of the circle that are parallel to the line $a$. 


\section{Figure 2. Tangents of the circle}

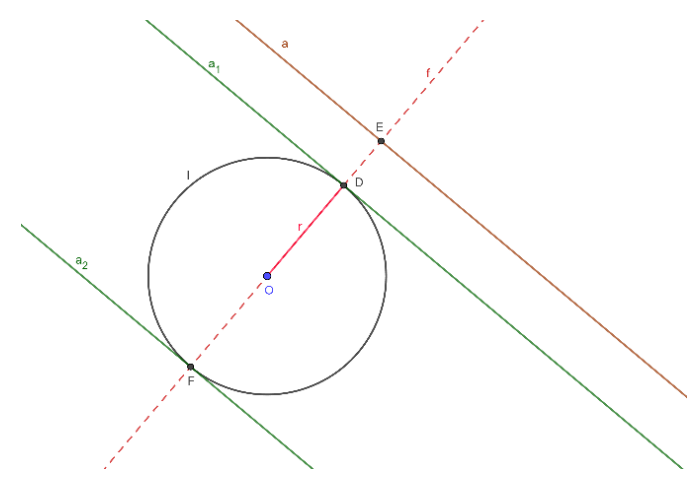

Students are first explained what a tangent is. It then begins with its construction in GeoGebra. Through the command Circle with Center Point we present the circle and move on. Based on the research, it turns out that students have a $100 \%$ participation. Each student tries to give the maximum along the software construction. The construction here does not present unclarity and each student shows curiosity about the lesson. The easiest part of the explanation is that the software enables the movement of the point through which the tangent is constructed. This movement helps in the perception of the movement of the tangent through the circular line.

In classical teaching with geometric tools students also construct following the teacher. However, the accuracy of the construction depends on the skill of the student in using the tools. Secondly, students perceive the tangent as a line that only exists at the point where it is constructed.

These differences are observed in 23\% of students, while the rest don't show any differences between the two methods. Most students, especially those above average, use GeoGebra construction as an outcome or example of how construction should look like in the end.

\section{Power of a Point}

The potency of a point $P$ to a circle is the product of the segments $P A$ and $P B$ where $P$ is the starting point of the first segment $(A B)$, and the last points of the segments $P A$ and $P B$ are points $A$ and $B$. And points $P, A$ and $B$ belong to the same line. With this definition, which is unclear to students, the potential explanation begins.

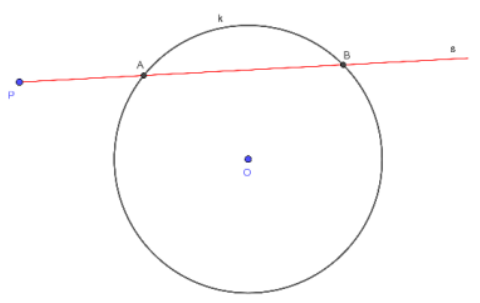

Figure 3. Power of a point

The key to our research is to encourage thinking in young people. Learning the potential of the circle is probably not for their age, but it encourages them to think. So here we tested both methods, software, and classic.

In the classical method we drew all the cases with tools. The students did the same. Here we go in the figure clarification part. The most difficult lesson, but also the perception, was zero. Here we cannot say that the students were different from each other. So, one thing was noticed: in some lessons or chapters perhaps, the first explanation of the lesson is better done with software. We came to this conclusion because learning about the power of point, with the classical method, in young students, was a failure. But when we did the potency cases with software, the situation changed. Since the figure could now move, the students had a different reaction. Understanding increased, the perception of the figures was higher, and classroom activity raised. 

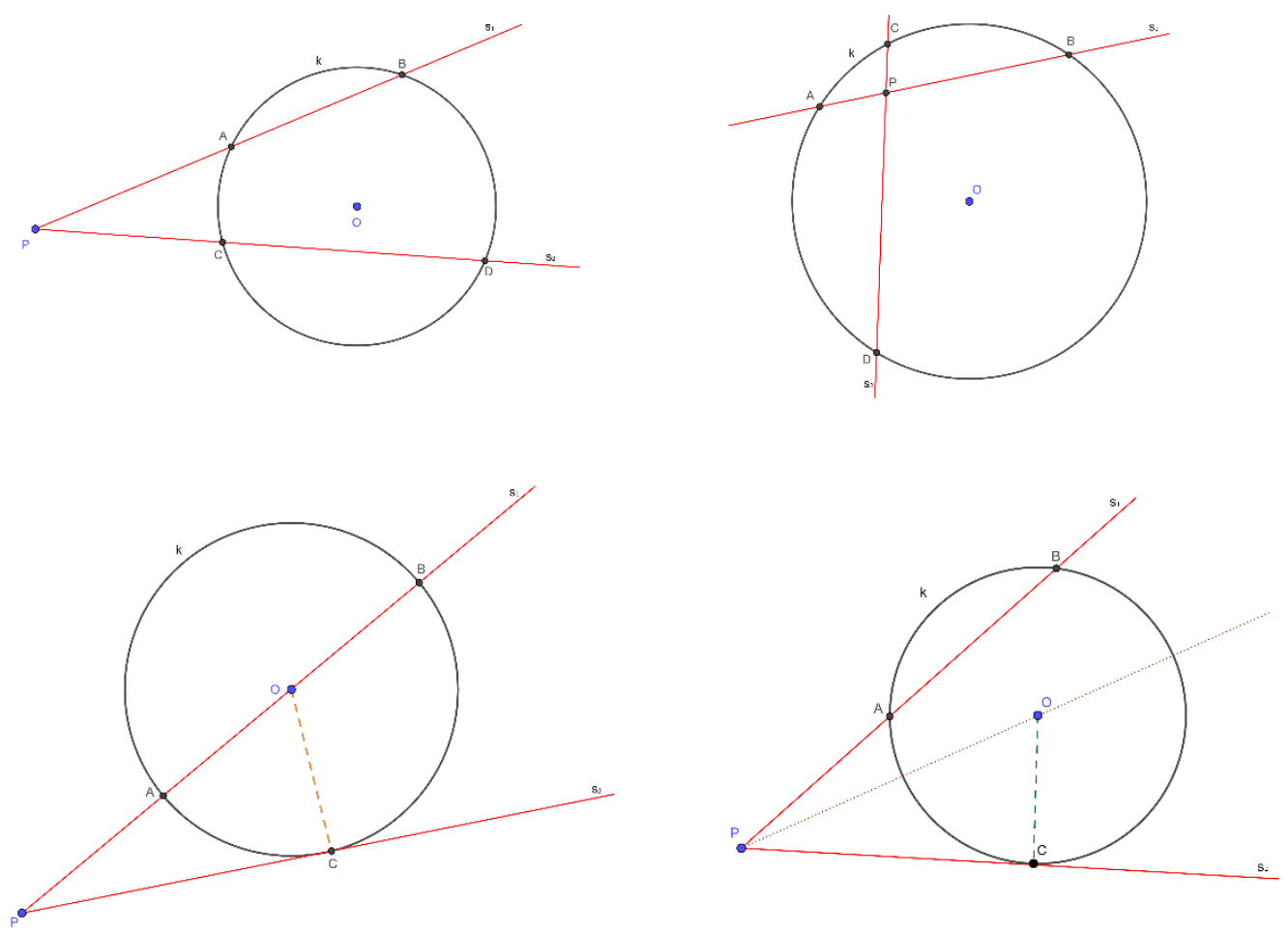

Figure 4. Power of point

Example 2. Mount Korab rises $2751 \mathrm{~m}$ above sea level. How far is the furthest point which can be seen from the top of this mountain? (The radius of the earth is $6371 \mathrm{~km}$ ).

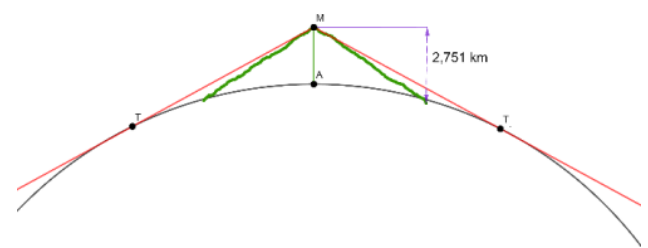

Figure 5. Sketch of Mount Korab



Figure 6. Power of point according to sketch

$$
\begin{aligned}
& M T^{2}=M A \cdot M B \\
& M A=2,751 \\
& M B=M A+2 r \\
& M B=2,751 \mathrm{~km}+2 \cdot 6371 \mathrm{~km} \\
& M B=2,751 \mathrm{~km}+12742 \mathrm{~km}
\end{aligned}
$$

$$
\begin{aligned}
& M B=12744,751 \mathrm{~km} \\
& M T^{2}=2,751 \mathrm{~km} \cdot 12744,751 \mathrm{~km} \\
& M T^{2}=35060,81 \mathrm{~km}^{2} \\
& M T=\sqrt{35060,81 \mathrm{~km}^{2}} \\
& M T=187,24 \mathrm{~km}
\end{aligned}
$$

The research showed that with the classical method the comprehension of the lesson was $0 \%$. With the software method, $27 \%$ of students, because they did not start on time, had problems with learning, $22 \%$ constructed the elements, $36 \%$ constructed and understood, $15 \%$ constructed, understood, and were able to explain. 
The district's potency highlighted a new statistic even in the average, perhaps because only students above average could meet this challenge.

\section{IMPLEMENTATION OF CIRCLE IN REGULAR POLYGONS}

The circle can be inscribed and circumscribed in any regular polygon.

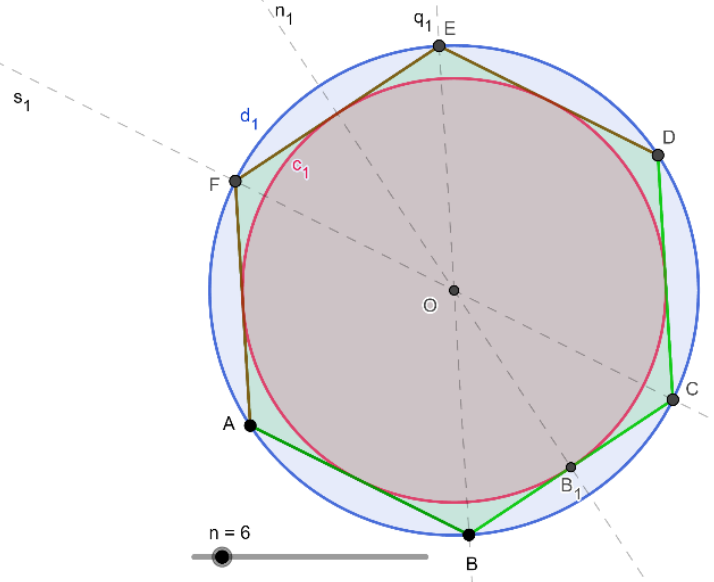

Figure 7. Circumscribed and inscribed circle in a regular hexagon

Example 4. Outline the circle into squares.

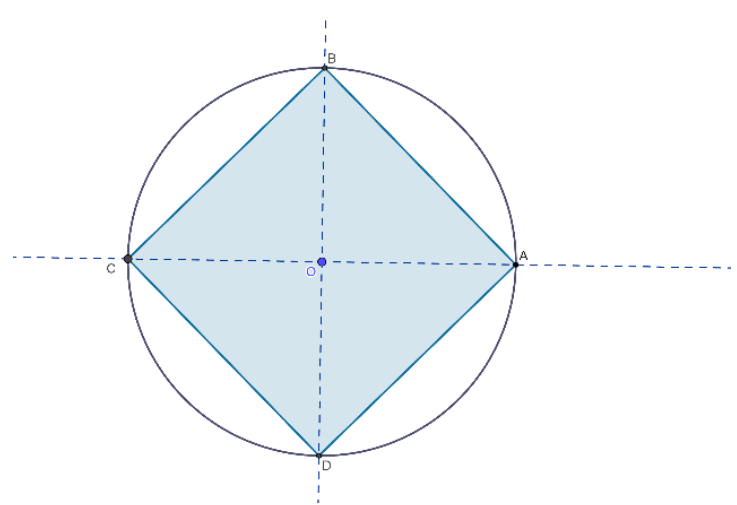

Figure 8. Circumscribed circle into square

The appearance of the inscribed and circumscribed circle as well as the possibility of moving (adding) from one regular polygon to another, at the same time, helps in the perception of the figure. Students, as soon as they see these movements, two situations arise:

1. They understand how the sides are added during the transition from one regular polygon to another.

2. Students see the inscribed and circumscribed circle through each figure.

In the above case, we are presented with a situation where students start and deepen in geometry. This figure and moving with it, present curiosity to them. At this point, there is almost no difference between students.

Statistics show that $89 \%$ of students constructed the figure in time, while $11 \%$ needed help.

The classical method of explanation slows us down but allows us to construct the figures ourselves. In the classical explanation, all figures are drawn separately, by tools. Here accuracy and result depend on the student. Inaccuracy makes the result impossible, and without accurate results, students do not perceive what they are doing. Job readiness is $100 \%$ for all students, but the focus on work and the pace of work is not the same for everyone. Students above average have no problems, are focused, have the same work pace as the teacher and the construction result is correct. While in students below average, first, the pace of work is very slow, many of the elements of construction are missing. Special emphasis is placed on symmetries, where many of them present them as ubiquitous lines, having lost the moment of their explanation. And in the end, they have neither the accuracy nor the perception of the figure. In construction with tools, in the classical form, we have: $12 \%$ of students which are behind with construction and do not even know what they are doing, 38\% know what they are constructing but, lag in some elements, $23 \%$ of students construct approximately well and $27 \%$ are accurate and have no problem with perception. 


\section{The Inscribed Circle in Equilateral Triangle}

In GeoGebra we first draw a triangle through the Polygon command. The students are then explained how the center of the inscribed circle is located. Further with the Angle Bisector command, we find the symmetries of the three angles. At the point of intersection of these three symmetries lies the center of the inscribed circle in the triangle. After creating the circle, students understand what they are creating. They start and move the triangle in different positions. They ask questions. The inscribed circle is a very important lesson as it makes the students very curious and arouses in them the desire for self-initiative.

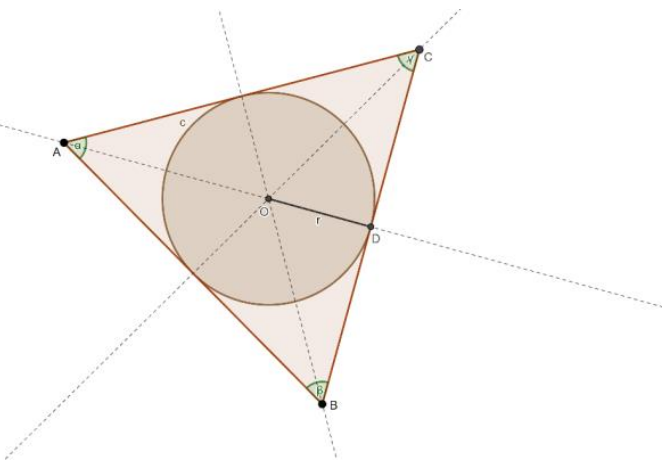

Figure 9. Inscribed circle

In the classical form, the tools of geometry are taken. First, it is shown that the main building element is the meeting of the symmetries of the angles at a point. During the work until the end of the construction, errors are noticed. For many students, the symmetries were not meet at one point. According to research, $88 \%$ of students fail to construct the center of the inscribed circle. While $12 \%$ of students build properly. In GeoGebra these problems do not occur. Looking at notebook work and GeoGebra work, students understand how it should be constructed.

\section{The Circumscribed Circle in an Equilateral Triangle}

After presenting the equilateral triangle, then through the Perpendicular Bisector command we find the midpoints of the sides. At their meeting point, $O$ is the center of the circumscribed circle in the triangle. Using command Center through Point, clicking on point $\mathrm{O}$, and then on point $\mathrm{A}$, we get a circle.

This is how students see their work. They know what they did, but they had a lot of questions. Among them were:

- If the symmetries do not meet, what happens?

- How do symmetries meet?

- Can we accidentally find the center of the circumscribed circle?

To answer, they have to do all the work themselves.

Let's get back to the classic form. Using geometric tools, we construct the triangle. There were answers to all the questions. The students' mistakes were the answer to their questions.

If the symmetries do not meet, we do not have the center of the circumscribed circle.

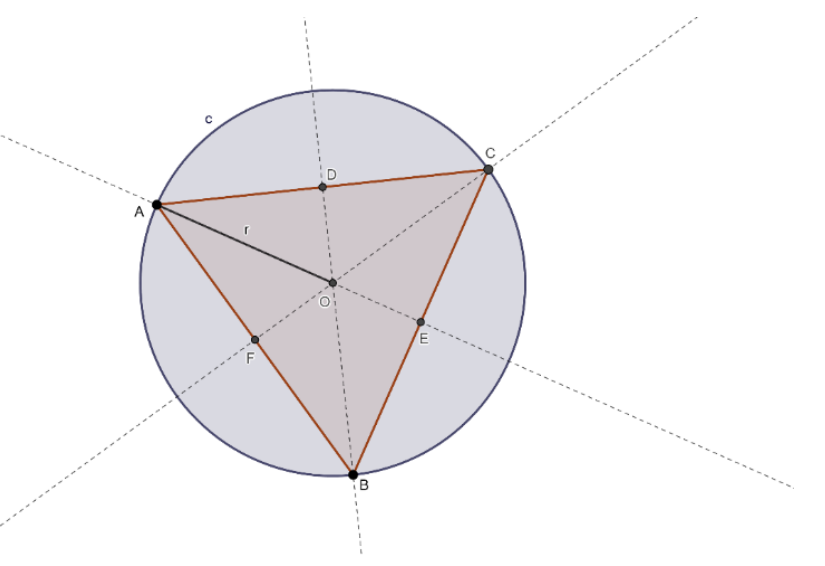

Figure 10. Circumscribed circle

When we construct correctly, the sides symmetries will meet. We were finally convinced that the center of the circumscribed circle was not found by chance. Research shows that $76 \%$ of students had many problems during construction with geometric tools. $24 \%$ had no problems. With GeoGebra, no student had any problems with construction. 


\section{FEW MISTAKES OF STUDENTS DURING CONSTRUCTION}

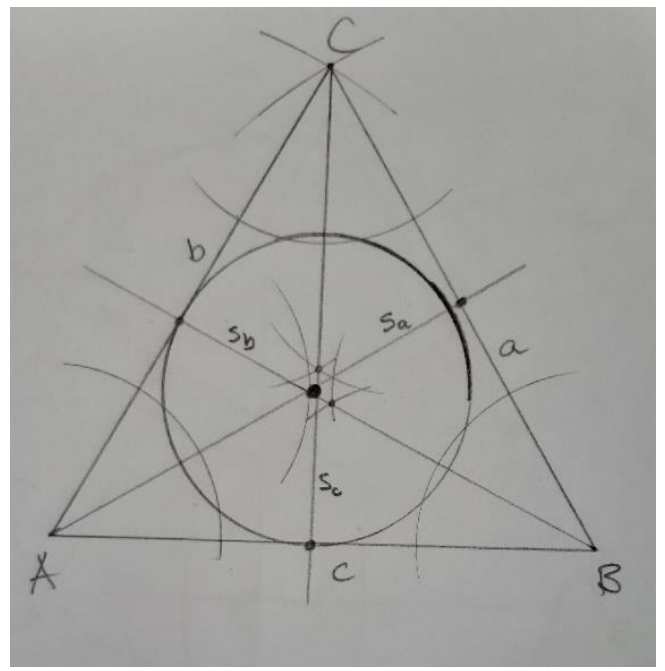

Figure 11. Meeting point enlarged



Figure 12. Circular and symetric lines thickened

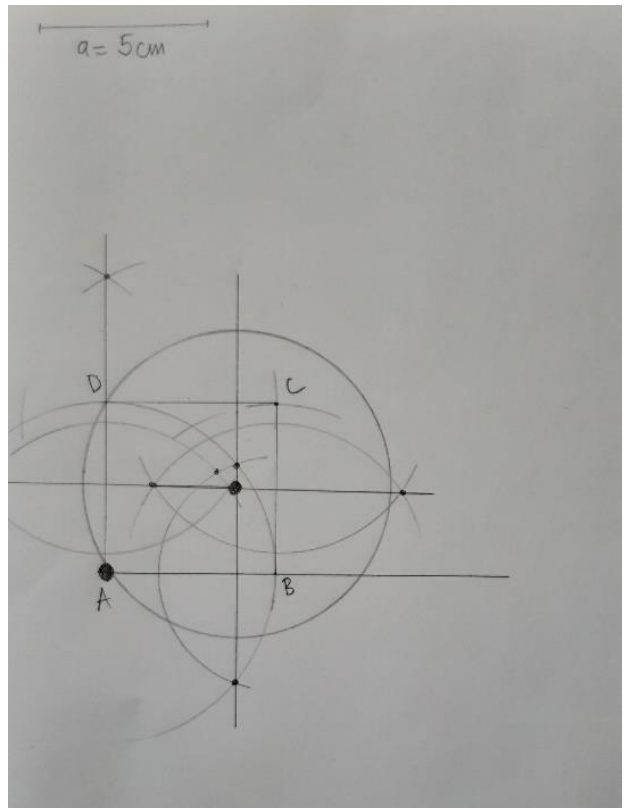

Figure 13. Symetric line found incorrect and enlarged points 




Figure 14. Filling the gaps

During the construction, the students, in the absence of experience with working with tools, made many mistakes. Besides, inaccuracy is noted. During the work, they try to: thicken the lines of the symmetries, thicken the sides of the polygons, thicken the circular lines, enlarge the meeting point of the symmetries, etc. Even when they find the symmetries of the sides, they are not even symmetrical. The line of the symmetry does not even fall between the sides. When the teacher asks about these mistakes, they do not know that they have made a mistake. They think that it is normal to interfere freely in the construction. All this happens during the joint construction with the teacher. Students above-average work correctly, while those below average do the above mistakes. To get all the students do the right thing, we worked with GeoGebra. Constructing using the software, all the students, without exception, noticed the exact construction work. They even realized how not to interfere freely.

So GeoGebra served us very well when we had to show students the average of what the work should look like at the end.

\section{SOFTWARE AND RESULTS}

Using GeoGebra in teaching, facilitates, accelerates, and makes geometry more tangible. During the explanation process, there is an increased interest and active participation of the students in the classroom through questions and discussion.

Worrying in our time is the fact that students are not convinced to devote themselves to learning, but technology. It cannot be said that they are completely wrong, as we have made great strides in technology, but not in teaching forms and techniques.

In this way, when the geometry is explained with GeoGebra, the lessons become very concrete. Students manage to perceive each figure.

This research was done to see the contemporary students, of the age of technology, how they would behave when taught geometry using software, always comparing the results with the classical forms of teaching. Every day we see students progressing in the use of technology. They enter different market places and download different software applications. Therefore, the second goal of this research was to acquaint students with applications in school and with scientific content. We included them in this experiment to see if they would be willing to adapt and work with software in school in addition to using it in their everyday lives. 


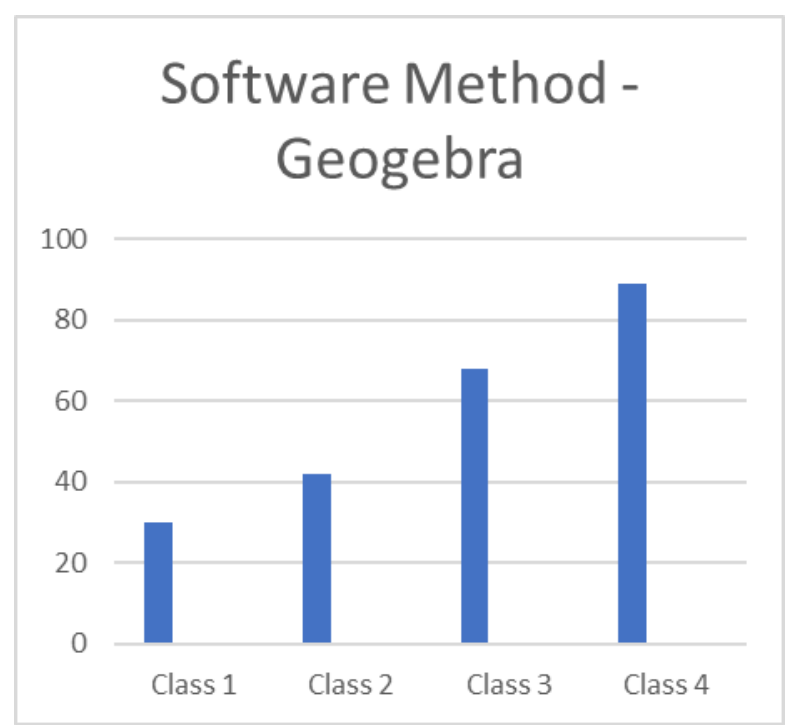

Figure 15. Software Method - GeoGebra

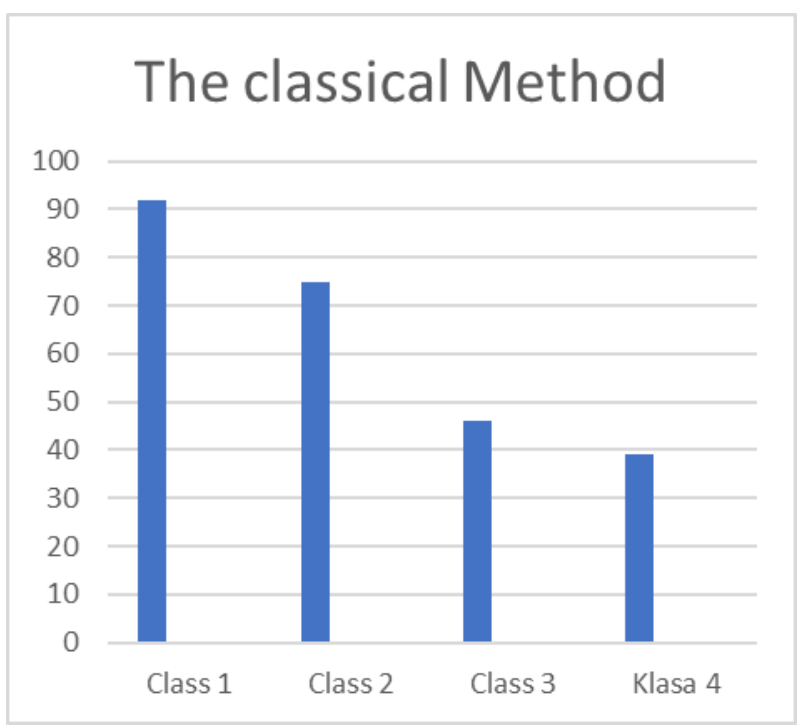

Figure 16. The Classical Method

Based on the research, when working with GeoGebra, the following results were obtained:

1. All students are active in the classroom and have a very scientific approach to learning

2. Success is noticed from the beginning and marks an increase

3. Students are curious and want to do other constructions themselves in GeoGebra

4. The younger ages work better and understand more with the classical form of teaching

5. Older students find themselves better when working with GeoGebra

\section{CONCLUSION}

The development of technology has given a strong blow to the classic way of reading books. In this way, it becomes increasingly difficult for teachers to provide quality in learning for all students alike. Based on this, every day we encounter the phenomenon of how students are increasingly moving away from learning, while increasingly immersed in the use of technology. If a student between the ages of 15 and 18 is taken 5 decades earlier, we see that this student spends his free time outside the home and spends his learning time at home, where the only source of information for learning is the book. The same student nowadays does not share the free cone and learning time, as technology (telephone, computer, ...) offers it all at the same time and in the same place. So, for a student, as he or she faces these experiences, either intentionally or unintentionally then it is almost impossible to convince him or her to learn from books and leave the gadgets aside.

Overall, research shows that students are very willing to learn geometry through GeoGebra. They are much more curious and school attendance is much higher. Critical thinking, understanding and interest are much higher when working with this software compared to not using any software. 
Classic geometric tools are suitable for teaching and learning but the probability of error is very high. Uncertainty, lagging during construction, giving up on lessons, along with the idea that learning is difficult, are some of the characteristics of students especially below average and intermediate students.

Students above average do not have problems with any form of explanation. Research shows that exploring GeoGebra attracts more students to learn math. The presentation of the circle properties to students using GeoGebra is very clear and makes them very curious.

\section{REFERENCES}

Dunn, J. A., \& Pretty, J. E. (1972, May). Halving a triangle. Mathematical Gazette, 56(396), 105-108. https://doi.org/10.2307/3615256 Encyglopedie Generale Larousse. (1967). Tome II Mathematiques (pp. 117). Librairie Larousse, Paris.

Geogebra Sofware, version 6.0. (n.d.). Dynamic Math for Everyone. Retrieved from https://www.geogebra.org/?lang=en

Heinbockel, J. H. (2017). Geometry. Retrieved from http://www.math.odu.edu/ jhh/geometry.pdf

Longuet-Higgins, M. S. (2009, March). On the ratio of the inradius to the circumradius of a triangle. Mathematical Gazette, 87(508), 119-120. https://doi.org/10.1017/S0025557200172249

Trianglesproperties and types. (n.d.). GMAT GRE Geometry Tutorial, MBA CrystalBall. Retrieved from https://www.mbacrystalball.com/blog/2015/10/16/triangles-properties-types-geometry/

Zeidler, E. (2004). Oxford Users' Guide to Mathematics. Oxford University Press. 